\title{
A Thyristor Based Series Power Flow Control Device for Multi-Terminal HVDC Transmission
}

\author{
Tianqi Zhang \\ Cardiff University \\ ZhangT14@,cardiff.ac.uk
}

\author{
Chuanyue Li \\ Cardiff University \\ LiC23@,cardiff.ac.uk
}

\author{
Jun Liang \\ Cardiff University \\ liangi1@,cardiff.ac.uk
}

\begin{abstract}
This paper achieves flexible power flow control by inserting a DC voltage to a line of MTDC transmission. A thyristor based power flow control device is designed to generate this inserted DC voltage. Three-phase six-pulse rectifier using thyristor can convert an $\mathrm{AC}$ voltage from $\mathrm{AC}$ generator or $\mathrm{AC}$ grid to a DC voltage. Power exchange occurs between the $\mathrm{AC}$ voltage terminal and DC grids without causing extra power losses which would be found if an inserted resistance is used. A control system is designed for the device and for the power flow control. This design is simulated by using PSCAD/MTDC and evaluated under different operation conditions. The control system is evaluated. Power flow control method is evaluated. This simulation proves the capability of the device to control the power flow effectively.
\end{abstract}

Index Terms-- Multi-Terminal HVDC, Series Power Flow Controller, Thyristor.

\section{INTRODUCTION}

In 2009, the EU and the G8 Heads of Government announced a target to reduce $80 \%$ of greenhouse gas emissions according to the levels of 1990 by 2050 . In order to meet this target, HVDC is considered as the key technology for the dc grid development. A huge dc grid named Super Grid allowing the massive integration of renewable sources in European power system will be developed over the whole Europe and the MENA region. Friend of the Super grid (FOSG) has proposed its Phase I plan as a demonstration project to build a dc grid in the North Sea due to its huge wind resources for offshore wind power delivery. The North Seas Countries' Offshore Grid Initiative (NSCOGI) and Offshore Grid plan to develop the dc grid in the North Sea as well.

Compared with HVAC, HVDC has obvious advantages in the aspects of economics, interconnection of power networks, long distance bulk power delivery and environmental benefits [1],[2]. Thus, HVDC transmission technology is a more feasible and economical solution of connecting offshore wind farms to the main grid.

There are a variety of converter topologies to achieve flexible power flow control in HVDC grid. LCC-HVDC, also called conventional HVDC, is used for bulk power transmission. [3],[4]. It is a mature technology that has proven its robustness through the years. The voltage level of Zhundong-

Sichuan project based LCC-HVDC which will be commissioned in 2015 can reach to $1100 \mathrm{kV}$ [5].
However, LCC-HVDC requires a strong ac grid reactive power support and voltage polarity change in power reversion. In 1990s, the voltage-source converter (VSC) based on IGBTs has entered the HVDC markets and the first VSC-HVDC project was commissioned in 1997[6]. It has the features of fully power control, connection to weak ac systems, no polarity reversal required to reverse the power flow and the small footprint of converter station[7],[8]. Up to now, the voltage level of VSC-HVDC reaches to $\pm 320 \mathrm{kV}$ [9].

The advantages mentioned above make VSC-HVDC technology be a preferred choice in Multi-terminal HVDC (MTDC) system. MTDC consisting of more than two converters is a flexible and reliable way for the interconnection between large scale of wind farms and ac grids [10].

As more and more wind farms and $\mathrm{AC}$ main grids are connected to the MTDC, a meshed HVDC grid will be formed [11].The redundancy of the meshed HVDC grid provides much more reliability than point-to-point HVDC links, which ensures the continuity and good quality of power delivery.

However, the power flow within the MTDC cannot be fully controlled by the VSCs only. Thus, flexible power control of DC grids is needed to realize the economic operation and power trading prevent overload of DC lines in post-fault conditions [12].

In MTDC networks, it is possible to control the active power flow in the line or in other parts of the system [13]. Thyristor-based power flow control (TPF) is a potential method to achieve flexible power flow. This TPF controller has the ability to combines the benefits of the robust and efficient LCC-type converter and the controllability of the advanced self-commutated technology such controller gives greater flexibility to HVDC transmission [14].

In this paper, TPF controller is series connected with the transmission line between two terminals to avoid high line losses in MTDC networks. TPF controller is used to control the current in the line to achieve the flexible power flow and protect this transmission link from disturbances in MTDC networks. Eventually, the simulation proves the capability to control the power flow effectively. The paper is organized as follows: Section 2 describes the methods to achieve power flow control, and Section 3 details the thyristor power flow control device. Section 4 shows the multi-terminal HVDC. 
Finally, Section 5 specifies the procedure of simulation and presents simulation result. The conclusion is in Section 6 .

\section{METHODS TO ACHIEVE POWER FLOW CONTROL}

Two types of control methods, the variable resistor and series voltage source, are presented to achieve the power flow control. [15]

\section{A. Variable Series Resistor}

According to the Ohms Law, the power flow within a meshed grid is mainly determined by resistances. So, a series resistor can be inserted in a DC grid to change the admittance of the lines directly.

The merit of the variable resistor is the low power rating and the simple structure. The drawback of series variable resistors is leading high power losses. Meanwhile, the control range of series variable resistor is restricted by its resistor[16].

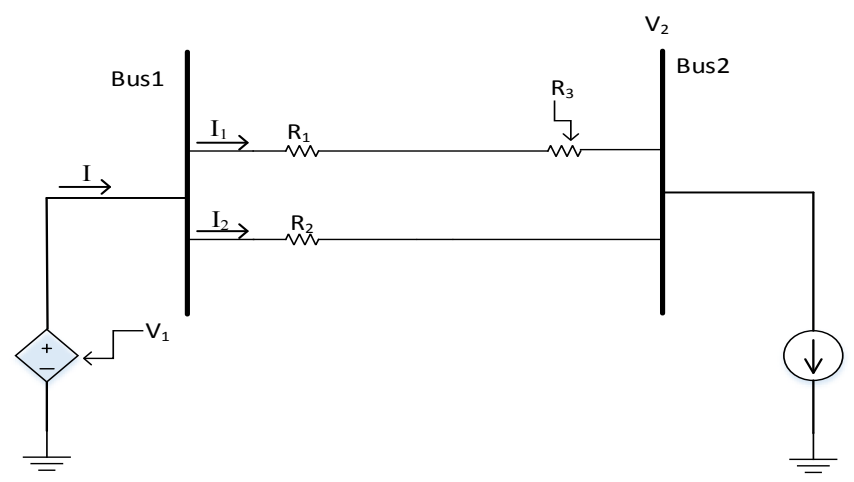

Fig. 1. Circuit with various series resistor

$$
\begin{aligned}
& I_{1}=V_{1}-V_{2} / R_{1}+R_{3} \\
& I_{2}=V_{1}-V_{2} / R_{2}
\end{aligned}
$$

\section{B. Series Voltage source}

The series voltage source is satisfied in all the aspects with the required flexibility of control, the feasible power rating and low power losses. So in terms of the cost, power losses, and control performance, series voltage source is an excellent choice to achieve flexible power control [17].

As can be seen from Fig.2, line 1 and Line2 are in parallel, so voltage on each line should have the equal value. In addition, reactance on L1 and L2 are equal and the current on each line should be same as well as the power flow.

$$
\begin{gathered}
I_{1}=V_{1}-V_{2} / R_{1} \\
I_{2}=V_{1}-V_{2} / R_{2}
\end{gathered}
$$

According to Fig.3, since a voltage is inserted into the Line1, the current on L1 and L2 are different. Meanwhile, the voltage on each line is the same, thus power on L1 and L2 are not equal.

$$
\begin{aligned}
& I_{1}=V_{1}-\Delta V-V_{2} / R_{1} \\
& I_{2}=V_{1}-V_{2} / R_{2}
\end{aligned}
$$

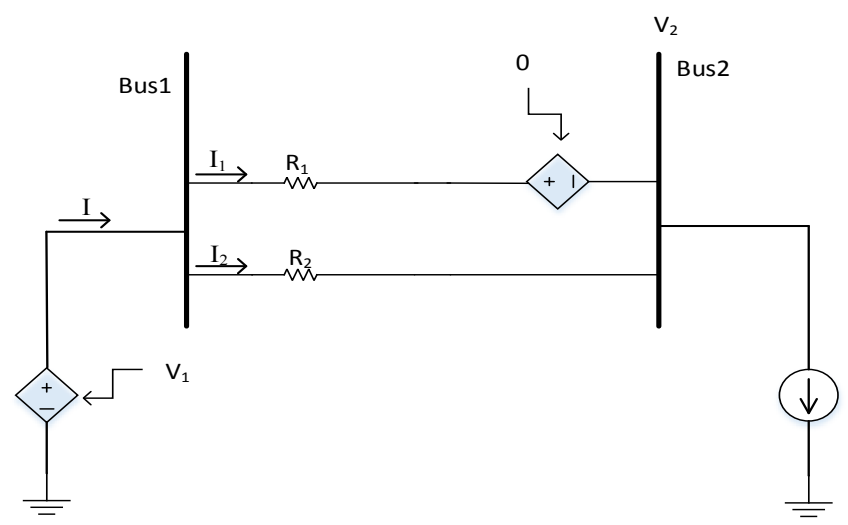

Fig. 2. Circuit without inserting voltage

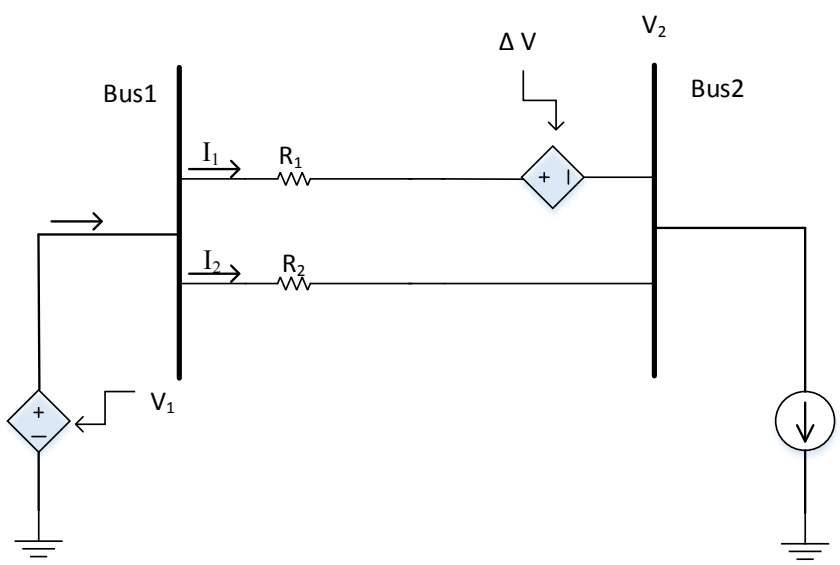

Fig. 3. Circuit after inserting voltage

\section{THYRISTOR POWER FLOW CONTROL DEVICE}

The Graetz Bridge also known as six-pules bridge consisted of 6 thyristors is connected to three balanced sinusoidal voltage sources on the ac side, the dc side will be series connected into the MTDC networks, depicted in Fig 4. This TPF controller is a thyristor-based six-pulse rectifier which can achieve flexibility power control.

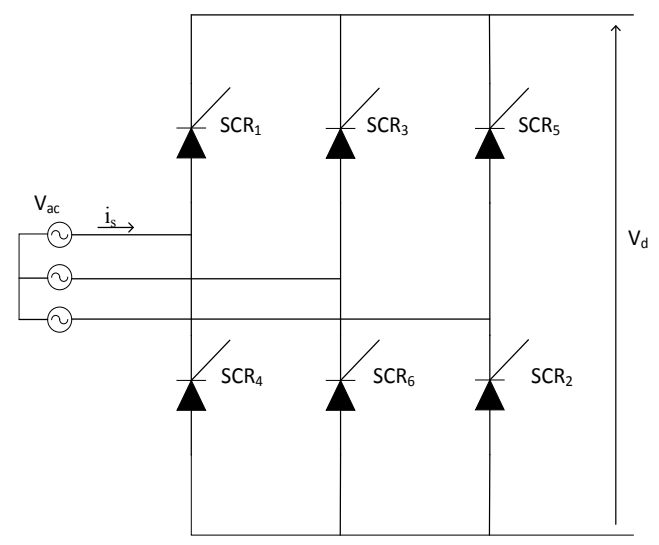

Fig. 4 Three phase full wave bridge controlled rectifier 
In order to give a clear explanation of the rectifier operation, there are two situations applied which are the SCR1-SCR6 are diodes and the SCR1-SCR6 are thyristors respectively.

\section{A. The SCR1-SCR6 are diodes}

The diodes have no turn-on or turn-off ability, the each pair of diodes is conducted $60^{\circ}$ per cycle, and the conduction sequence is shown in Table 1. According to Table 1, the actual conduction time of one diode is $120^{\circ}$. Due to the Graetz Bridge, the three balanced sinusoidal voltage is converted to a cyclical string of small ripples (six ripples per cycle) as the output of rectifier. The mean value of these ripples is treated as a dc output voltage. The relationship between DC output and AC voltage is shown below:[18]

$$
\mathrm{V}_{\mathrm{d}}=3 \sqrt{2} / \pi \mathrm{V}_{\mathrm{ac}}
$$

$\alpha$ is the terminal voltage of dc side, Vac is the rms line-toline voltage of ac side.

TABLE I

DIODES' CONDUCTION SEQUENCE AND TIME

\begin{tabular}{|l|c|c|c|c|c|c|}
\hline Number & $12^{\circ}$ & 23 & 34 & $45^{\circ}$ & 56 & 61 \\
\hline Duration & $60^{\circ}$ & $60^{\circ}$ & $60^{\circ}$ & $60^{\circ}$ & $60^{\circ}$ & $60^{\circ}$ \\
\hline
\end{tabular}

\section{B. The SCR1-SCR6 are thyristors}

The thyristor can treat as the diode with turn-on ability. Each pair of thyristors matches one ripple in one cycle. A delay time is applied on the gate of thyristors to decide when to turn on. It is common to refer this delay time in terms of the electrical degrees $0^{\circ}$ and this delay angle is referred to as firing angle. The shape of the ripples is depend on the firing angle, thus the mean value of cyclical ripples can be controlled by firing angle, which means the firing angle has the ability to control the output dc voltage. The function between firing angle and output dc voltage is shown below[19]:

$$
\mathrm{V}_{\mathrm{d}}=3 \sqrt{2} / \pi \mathrm{V}_{\mathrm{ac}} \cos \alpha
$$

$a$ is firing angle. At, the thyristors $\alpha=0$, can be considered to be operating as diodes.

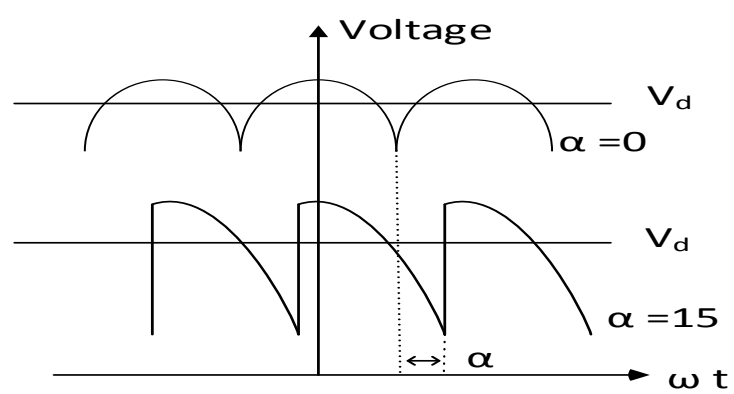

Fig. 5. Waveforms of $\mathrm{V}_{\mathrm{d}}$ with different firing angles

\section{MULTI-TERMINAL HVDC}

The basic structure of the system considered in this project is shown in Fig 6.

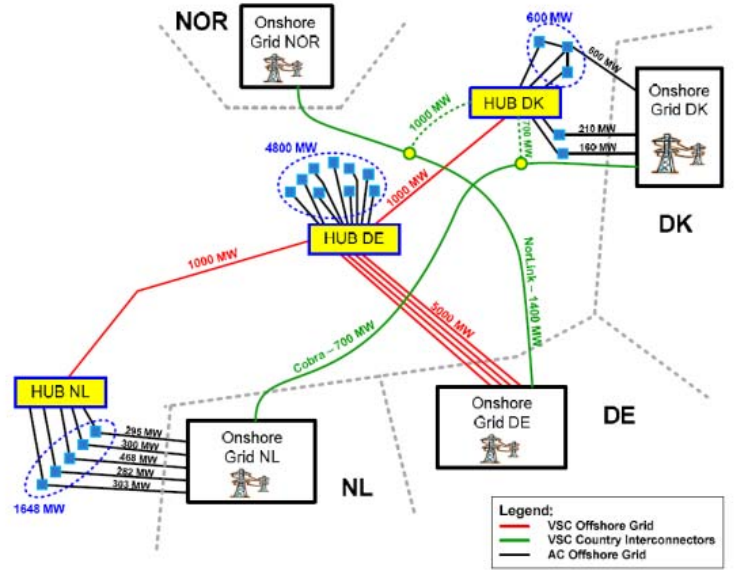

Fig.6. Basic structure of the test system [20]

Fig.6 describes a North Sea meshed multi-terminal DC grid four countries which are Norway, Denmark, Germany and Netherland.HUB DK, HUB DE and HUB NL represent the offshore hubs of the three countries Denmark, Germany and Netherland respectively. These hubs are connected to the region with high forecasted installed wind capacity. VSCHVDC links are used as the interconnections among hubs and countries.

The supposed simplified system based on the Fig.6. is shown in Fig.7. This paper focuses on flexible power flow control within dc networks, the ac links are ignored and Cobra link is removed in supposed system due to its little influence on total de networks.

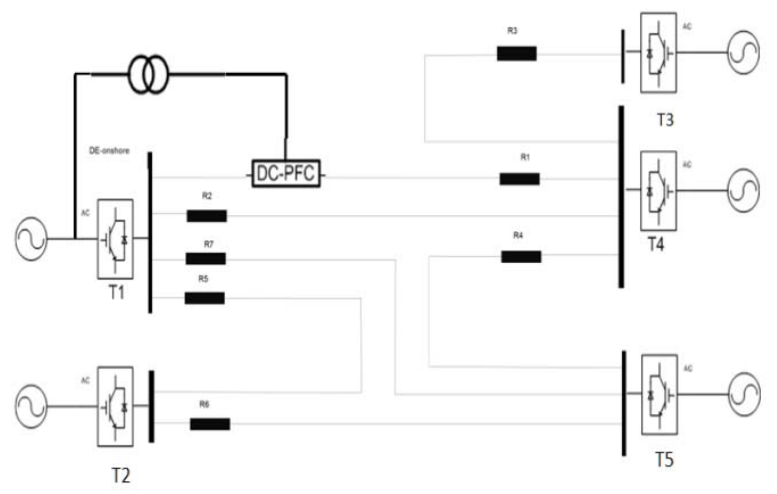

Fig.7. The simplified network of multi-terminal HVDC system

The information about transmission lines among onshore grids and hubs are detailed in Ref. [20], the parameters between each terminal can calculated and shown in Table II.

TABLE II

THE PARAMETERS OF EACH LINE

\begin{tabular}{|c|c|c|}
\hline Branch & Resistance/( $\mathbf{\Omega})$ & Inductance/(H) $(\mathbf{H})$ \\
\hline L1 & 0.6224 & 0.0213 \\
\hline L2 & 0.2426 & 0.0064 \\
\hline L3 & 0.8316 & 0.0350 \\
\hline L4 & 0.5858 & 0.0247 \\
\hline L5 & 0.8686 & 0.0366 \\
\hline L6 & 1.4367 & 0.0605 \\
\hline L7 & 0.7651 & 0.0322 \\
\hline
\end{tabular}


There are five terminals. T1 is DE_onshore which is represented as an inverter to provide a constant output voltage to the system. T2 represents NOR_onshore. The out loop control which is consisted by active power controller and reactive power controller provides reference $I_{d-r e f}$ and $I_{q-r e f}$ for the inner current loop control [21]. T3 is NL_HUB which is controlled by current controller and reactive power controller.T4 and T5 are DE_HUB and DK_HUB respectively. Both of the mare inverters which are controlled by active power controller and reactive power controller. And can also supply reference $\mathrm{I}_{\mathrm{d}-\mathrm{ref}}$ and $\mathrm{I}_{\mathrm{q}-\text { ref }}$ for the inner current loop control.

Finally, the power rating and voltage profile of each terminal are shown below:

$$
\text { TABLE III }
$$

THE PARAMETER OF PI CONTROLLERS OF EACH TERMINAL

\begin{tabular}{|c|c|c|}
\hline \multirow{2}{*}{ Terminal } & Type of PI controller & $\begin{array}{c}\text { Reference } \\
\text { Value }\end{array}$ \\
\hline \multirow{2}{*}{ DE_onshore } & Voltage & $300 \mathrm{kV}$ \\
\cline { 2 - 3 } & Reactive power & $10 \mathrm{MVAr}$ \\
\hline \multirow{2}{*}{ NOR_onshore } & Active power & $-300 \mathrm{MW}$ \\
\cline { 2 - 3 } & Reactive power & $5 \mathrm{MVAr}$ \\
\hline \multirow{2}{*}{ NL_HUB } & Current & $0.275 \mathrm{kA}$ \\
\cline { 2 - 3 } & Reactive power & $2 \mathrm{MVAr}$ \\
\hline \multirow{2}{*}{ DE_HUB } & Active power & $-320 \mathrm{MW}$ \\
\cline { 2 - 3 } & Reactive power & $10 \mathrm{MVAr}$ \\
\hline \multirow{2}{*}{ DK_HUB } & Active power & $-280 \mathrm{MW}$ \\
\cline { 2 - 3 } & Reactive power & $8 \mathrm{MVAr}$ \\
\hline
\end{tabular}

The simulation model is shown below:

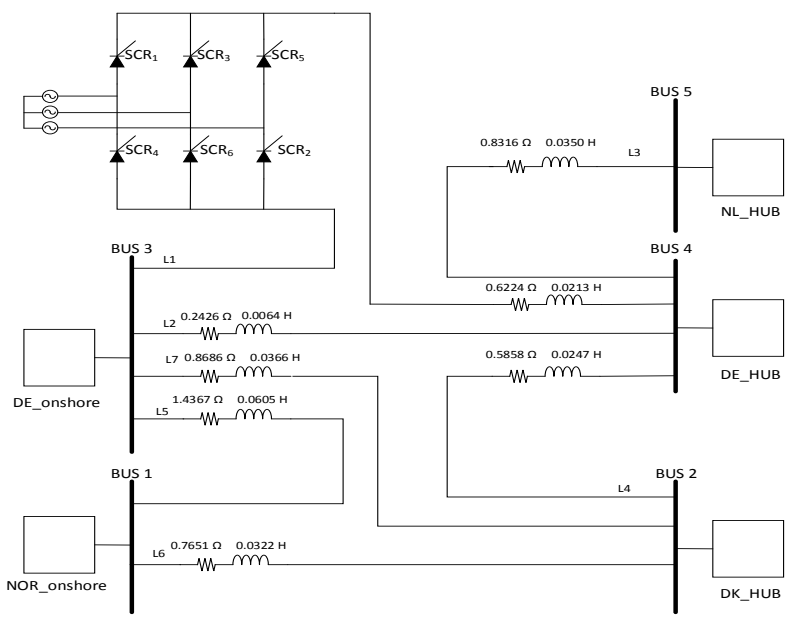

Fig.8. Simulation model

As shown in Fig.8, there is a TPF controller with input AC voltage of $0.415 \mathrm{kV}$ series in L1. A phase looked loop and a current PI controller (proportional gain -10 and integral time constant 0.05 ) is employed to control the current on L1.

\section{SIMULATION RESULTS AND DISSCUSSION}

Fig.9 shows the relationship between firing angle and the output voltage on rectifier. The output voltage is positive for $0^{\circ}<\alpha<90^{\circ}$, and for $90^{\circ}<\alpha<180^{\circ}$, the output voltage becomes negative.

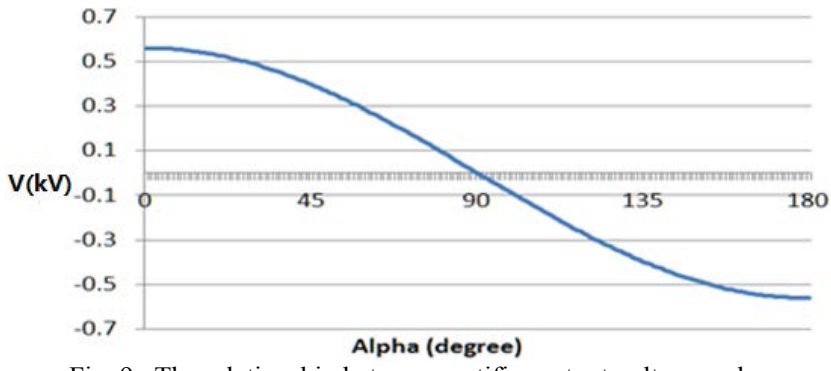

Fig. 9. The relationship between rectifier output voltage and $\alpha$

The voltage controller is introduced to control the voltage in DE_onshore. The reference value for voltage is $300 \mathrm{kV}$, and changes to $280 \mathrm{kV}$ and $320 \mathrm{kV}$ at $10 \mathrm{~s}$ and $18 \mathrm{~s}$ respectively. According to fig.10, the voltage controller has the capability to control the voltage.

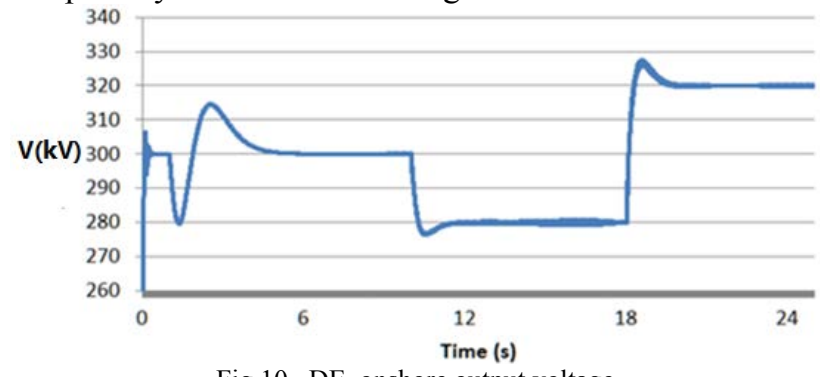

Fig.10. DE_onshore output voltage

The current controller is employed to control the TPFC. The reference value for $\mathrm{L} 1$ is $0.6 \mathrm{kA}$, then increase to $0.8 \mathrm{kA}$ and $1.0 \mathrm{kA}$ at $10 \mathrm{~s}$ and $18 \mathrm{~s}$ respectively. According to fig. 11 , the current controller engages to control the current through L1.

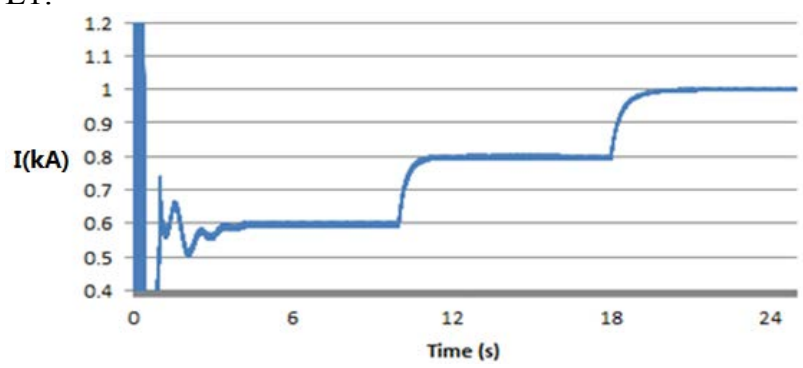

Fig.11. Current through line L1

The reactive power controller is employed in DE_HUB. The reference value for $\mathrm{Q}$ is $5 \mathrm{MVAr}$, and increase to $\overline{15}$ and $30 \mathrm{MVAr}$ at $10 \mathrm{~s}$ and $18 \mathrm{~s}$ respectively. According to fig.12, the reactive power controller can control the $\mathrm{Q}$ efficiently.

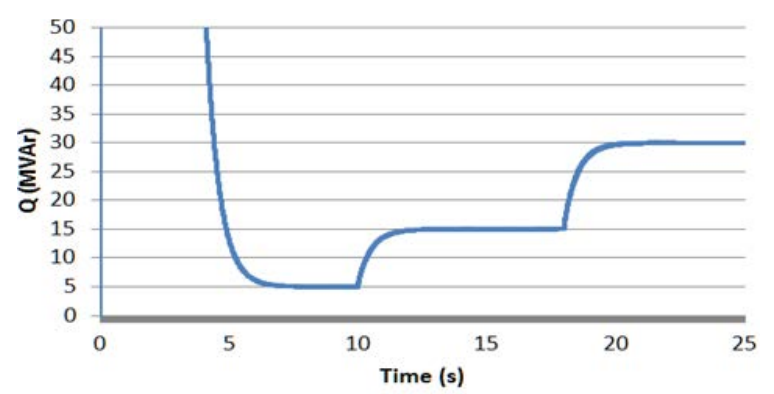

Fig.12. Reactive power in DE_HUB

Assume that the maximum capacity on the line 1 is 1.3 $\mathrm{kA}$, and then break up L2 at 5 seconds. According to fig.13, 
the current on $\mathrm{L} 1$ is changed to $1.3 \mathrm{kA}$ from $1 \mathrm{kV}$ to reduce the power losses on L2.

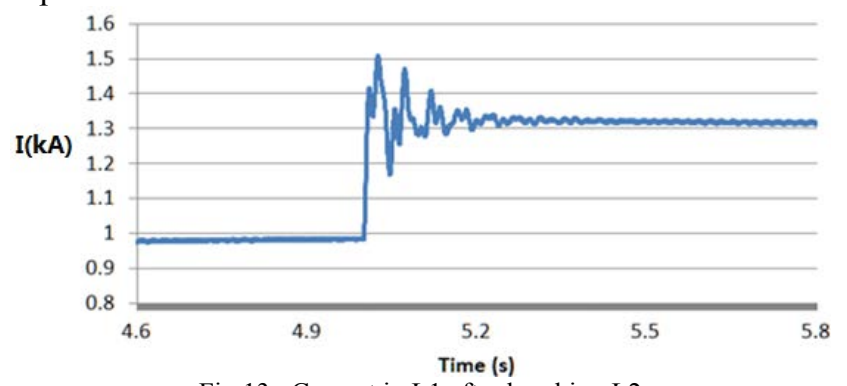

Fig.13. Current in L1 after breaking L2

Power in DE HUB terminal decreased from 320MW to 290MW. Fig. 14 shows the variation of current in L1 and L2. Compared with L2 without controller, the fluctuation is less for L1 with rectifier controller, which indicates that the PI controller for L1 has such an excellent performance in current control that the changes in terminal's power flow have a negligible effect on current of L1.

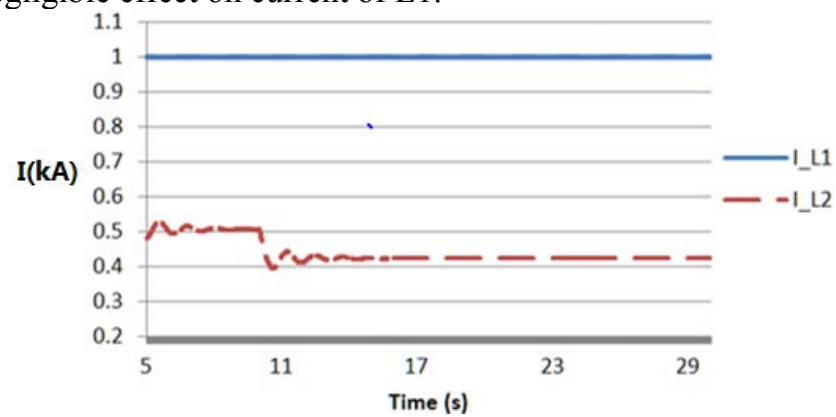

Fig.14. Current in I_L1 and I_L2 during the power changes in DE_HUB

\section{CONCLUSION}

In this paper, a six-pulse thyristor bridge based power flow controller is used to generate DC voltage. This DC voltage is inserted in the DC grid and then to control power flexibly without causing high power losses.

Meanwhile, a five terminal VSC based DC grid is designed. Then the power flow controller is in series in one transmission line of the DC grid. In this simulation, the control system is designed and evaluated on the different designed control system. By using PSCAD, the system is simulated to test the control system and the device. Eventually, this simulation proves the capability to control the power flow effectively.

\section{ACKNOWLEDGEMENT}

Parts of Chuanyue Li's work were supported by China Scholarship Council under the project 201408060016.

\section{REFERENCE}

[1] Wang H, Redfern M A. The advantages and disadvantages of using HVDC to interconnect AC networks[C]//Universities Power Engineering Conference (UPEC), 2010 45th International. IEEE, 2010: 1-5.

[2] M. P. Bahrman, "HVDC Transmission Overview" IEEE/PES T\&D, Transmission and Distribution Conference and Exposition, 2008. DOI: 10.1109/TDC.2008.4517304.
[3] Dierckxsens C, Srivastava K, Reza M, et al. A distributed DC voltage control method for VSC MTDC systems[J]. Electric Power Systems Research, 2012, 82(1): 54-58.

[4] W. Lu and B. T. Ooi, "Premium quality power park based on multiterminal HVDC," IEEE Trans. Power Del., vol. 20, no. 2, pt. 1, pp. 978-983, Apr. 2005.

[5] Scherer H N, Vassell G S. Transmission of electric power at ultra-high voltages: current status and future prospects $[\mathrm{J}]$. Proceedings of the IEEE, 1985, 73(8): 1252-1278.

[6] M. H. Okba, M. Z. Mostafa "High Voltage Direct Current Transmission - A Review, Part I”.

[7] G. Reed, R.Pape and M. Takeda "Advantages of Voltage Sourced Converter (VSC) Based Design Concepts for FACTS and HVDC-Link Applications ", 0-7803-7989-6/03, IEEE,2003.

[8] W. L. Kling, R. L. Hendriks, and J. H. den Boon, "Advanced transmission solutions for offshore wind farms," in Proc. 2008 IEEE Power and Energy Society General Meeting - Conversion and Delivery of Electrical Energy in the 21st Century, pp. 1-6.

[9] Seljeseth H, Saethre E A, Ohnstad T, et al. Voltage transformer frequency response. Measuring harmonics in Norwegian $300 \mathrm{kV}$ and $132 \mathrm{kV}$ power systems[C]//Harmonics and Quality of Power Proceedings, 1998.Proceedings.8th International Conference On. IEEE, 1998, 2: 820-824.

[10] LENNERHAG O, TRAFF V. Modelling of VSC-HVDC for Slow Dynamic Studies[J].

[11] Livermore L, Liang J, Ekanayake J. MTDC VSC Technology and its applications for Wind Power[C]//Universities Power Engineering Conference (UPEC), 2010 45th International. IEEE, 2010: 1-6.

[12] Adam G P, Anaya-Lara O, Burt G. Multi-terminal dc transmission system based on modular multilevel converter[C]//Universities Power Engineering Conference (UPEC), 2009 Proceedings of the 44th International. IEEE, 2009: 1-5.

[13] Chen H, Wang C, Zhang F, et al. Control strategy research of VSC based multiterminal HVDC system[C]//Power Systems Conference and Exposition, 2006. PSCE'06.2006 IEEE PES. IEEE, 2006: 19861990.

[14] Yousuf S M, Subramaniyan M S. HVDC and Facts in Power System[J]. International Journal, 2013.

[15] Pinto R T, Rodrigues S, Bauer P, et al. Operation and control of a multi-terminal DC network[C]//ECCE Asia Downunder (ECCE Asia), 2013 IEEE. IEEE, 2013: 474-480.

[16] Mu Q, Liang J, Li Y, et al. Power flow control devices in DC grids[C]/Power and Energy Society General Meeting, 2012 IEEE. IEEE, 2012: 1-7.

[17] Arrillaga J, Liu Y H, Watson N R. Flexible power transmission: the HVDC options[M]. John Wiley \& Sons, 2007.

[18] E. Veilleux, B.T. Ooi, "Multi-terminal HVDC With Thyristor PowerFlow Controller", IEEE TRANSACTIONS ON POWER DELIVERY, VOL. 27, NO. 3, JULY 2012.

[19] Marusarz R. Electronic circuitry to protect solid state switches from excessive locked-rotor current in appliances[J]. Consumer Electronics, IEEE Transactions on, 1989, 35(3): 630-634.

[20] Rudion, K. et al. 2010. Toward a Benchmark Test System for the Offshore Grid in the North Sea.IEEE Power and Energy Society General Meeting. San Diego, 22-26 July, 2012. Piscataway, NJ: IEEE Computer Society.

[21] Ouquelle H, Dessaint L A, Casoria S. An average value model-based design of a deadbeat controller for VSC-HVDC transmission link $[\mathrm{C}] / /$ Power \& Energy Society General Meeting, 2009.PES'09.IEEE. IEEE, 2009: 1-6 